Journal of Educational Research in Developing Areas (JEREDA)

Vol. 1. Issue 3, Pp. 202-213, 2020

http://www.jeredajournal.com

E-mail: info@jeredajournal.com

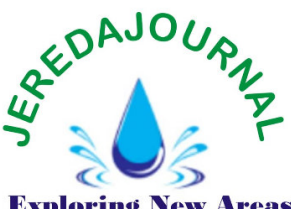

Exploring New Areas

Research Article DOI: https://doi.org/10.47434/JEREDA.

eISSN : $2735-9107$

\title{
EFFECTS OF SCHOOL LEADERSHIP IN ENHANCING LEARNERS' ACHIEVEMENT IN SOUTH AFRICAN RURAL SCHOOLS
}

\author{
${ }^{* 1}$ George Nervious Shava, ${ }^{2}$ Lwazi Sibanda \\ ${ }^{1,2}$ National University of Science and Technology, Bulawayo, Zimbabwe \\ Email.2sibandalwazi@gmail.com

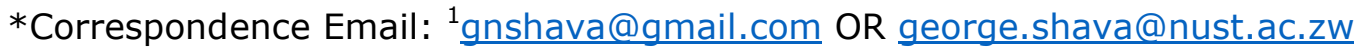 \\ (1) https://orcid.org/0000-0002-1890-9605
}

Received: $11^{\text {th }}$ November,2020; Revised: $23^{\text {rd }}$ November,2020 Accepted: $30^{\text {th }}$ November, 2020

\begin{abstract}
Introduction: School leadership has increasingly been gaining attention from educational policymakers, and the entire educational society. Research has also confirmed that school principals are essential for developing and maintaining effective school systems. The role of school leadership in schools is highly complex and dynamic such that strategies are needed to change underperforming schools. This article reported on a small scale exploratory qualitative study that investigated the effects of school leadership in enhancing the learning outcomes of a cohort of schools in a rural setting in South Africa.
\end{abstract}

Purpose: The purpose of the study was to analyse the role of principals in enhancing learning achievement in schools.

Methodology: The study took a qualitative research approach with an interpretive epistemological and constructivist ontological perspective. Qualitative evidence was collected from six schools in the same district through semi-structured interview question with educators and school principals. Purposive sampling techniques were used to select information-rich cases from the schools and in selecting the schools.

Results: Grounded in the accounts of our study participants, results from the study indicated that school principals are the cornerstones of achieving quality teaching and learning through motivating educators, training and providing distributed leadership

Recommendations: From the study findings, it was recommended that there is need to improve the basic unit of the educational institution which include structural, cultural and agential conditions to enhance the effective operations of school principals. There is a need to motivate and enhance existing forms of agency in ways that expand learners' achievement.

Keywords: Culture of achievement, culture of teaching and learning, decision-making leadership, learners' achievement, motivation, school climate

Crossref Shava, G. N., \& Sibanda, L. (2020). Effects of school leadership in Cited-by enhancing learners' achievement in South African rural schools. Journal of Educational Research in Developing Areas, 1 (3), 202-213. https://doi.org/10.47434/JEREDA.1.3.2020.202.

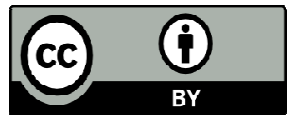

Copyright (c) 2020 The author(s) of this article retain(s) the copyright. 


\section{PUBLIC INTEREST STATEMENT}

The study was conducted in South African context of teaching and learning. The study is among the first empirical study to understand the role of school principals in enhancing learning achievement. The study used the critical realist theory by Roy Bhaskar to understand the interplay of structure, agency and culture in influencing learning achievement

\section{INTRODUCTION}

Research

has

repeatedly

confirmed that principals are essential for developing and maintaining successful and effective education systems (Heystek \& Minnaar, 2015). Principal leadership issues in schools are increasingly the subject of debate and exploration in international and comparative contexts, and there is unprecedented interest in how principals influence the performance of learners (Hoy, 2012). School leadership has been receiving growing attention from educational policymakers as research evidence indicates that principals together with their school management teams (SMTs) play a crucial role in improving learner performance (Shava \& Ndebele, 2016). While other factors within the school context may contribute to school turnaround, effective leadership is the main catalyst (Sayadi, 2016). To meet the many challenges of the 21st century and specifically those of the next decade, principals need to develop critical skills and strategies for providing a positive learning environment. Klar, Huggins, Hammonds and Buskey (2016) argue that the presence or absence of effective school leaders, a positive school climate and a positive attitude among teachers can directly or indirectly influence school performance and learner achievement. Without question, good leadership in schools can contribute to school improvement by stimulating motivation, participation and aspirations among teachers (Boylan, 2016). Maintenance of quality education and high standards in schools depends largely on the extent to which principals effectively carry out their leadership responsibilities. Principals need to create conditions to stimulate the morale of school members, utilising their higher level of leadership, making different members at different times either motivated or respected or trusted or satisfied and gradually reaching Volume 1, Number 3 consensus on the overall objectives of the school (Yang, 2014). In South Africa and the entire southern African region, there is growing concern that schools are not performing well. There are many school principals that lack the requisite knowledge and skills to lead their schools towards sustaining high-quality learning outcomes. This study seeks to explore the effects of school principals on enhancing learner achievement, particularly in the way principals deal with cultural, structural and agential factors that influence learning outcomes.

The study is structured into four main parts. Drawing from the literature, the first section of the article provides a literature review. In the process, it contextualises the study and thus explores the interplay of culture, structure and agency in enhancing learner achievement in schools. The second section of the article explains the research design and the methods adopted in the study. The third section focuses on the findings and discusses the data. A conclusion is presented in the final section.

\section{Leadership and school improvement}

The specific variables associated with improved learners' achievement and more specifically with improved school performance have been a focus of research in South Africa. The general assumption is that the presence of effective school leaders drawn from the principal and the school management team (SMT) creates a positive school climate and a positive attitude among teachers which can directly or indirectly influence the culture of teaching and learning in the school (Krüger, Witziers \& Sleegers, 2007; Waters, Marzano \& McNulty, 2004; Witziers, Bosker \& Krüger, 2003). In this article, we argue that while the relationship between effective school leadership and improved school performance appears to be 
relatively simple and straightforward in theory, in practice it is complex and unpredictable. Cotton (2003) argues that it is evident that a fundamental connection between the principal's leadership and school performance in terms of student achievement exists. Hallinger (2005:229), in his review of the impact of leadership on student outcomes concluded as follows: "The size of the effects that principals indirectly contribute towards student learning, though statistically significant, is also small." Harris (2004) and Storey (2004) assert that although the field of leadership is replete with often largely descriptive studies of effective leadership, these studies have rarely traced or explored with sufficient rigour the relationship between leadership and school performance. Harris (2004:4) explains that

[we do not know, for example, exactly what forms of leadership result in high performing schools across different school contexts, and in different types of schools. We do not know what particular combination of experience, training and professional development most benefits leaders wishing to improve their schools. Of most concern is the fact that we have very few studies that have explored the relationship between leadership and student learning outcomes in any depth. The correlational nature of the research evidence that does exist inevitably masks the exact patterning and nature of the relationship between leadership and enhanced student learning.

The literature on school improvement (Shava \& Heystek, 2015) sees the quality of leadership in schools as a key catalyst to organisational learning and improvement (Hoy, 2012; Robinson, Lloyd \& Rowe, 2008). Similar agreement is also evident in the contribution of leadership to the implementation of virtually all initiatives aimed at improving student learning and the quality of schools (Cosner, 2011).
Also, the Policy on the South African Standard for Principals, for example, in setting out the core purpose of principalship focuses strongly on the need to manage teaching and learning effectively to improve learner achievement (Department of Basic Education, 2016). This therefore, means that schools depend on leadership throughout the organisation to shape productive activities for both learners and educators. To increase the capacity to enhance the achievement of school goals, school leadership needs to adopt multiple models of leadership. This will sustain dialogue and decision-making (Hoy, 2012) related to improving educational matters.

\section{Agency and structure}

The theoretical lens used in this study to explore the role of leadership in schools in enhancing the culture of teaching and learning is Margaret Archer's (1995) social realist theory of structure, culture and agency. Critical realists believe that there is a reality independent of our thinking of it that science can study (Bhaskar, 1978). Critical and social realists focus (Bhaskar, 1978) on identifying hidden causal mechanisms, how they work, whether they are active or not, and the conditions under which they become active. In critical realism, a causal explanation for a given phenomenon is inferred by explicitly identifying how structural entities and contextual conditions interact to generate a given set of events (Wynn \& Williams, 2012). Critical realism observes that there is a reality which exists independent of human conception. According to Bhaskar (1978), the "realism" aspect of the theory focuses on the existence of real mechanisms which shape events. The "critical" aspect requires a deep understanding of any social situation, going beyond the observable and investigating the mechanism beyond any event (Bhaskar, 1978).

Critical realism adopts constructivists' ideas that all humans construct their views of the world based on their perceptions of it. Archer (1995) 
came up with culture, structure and agency as the three social reality elements that can be studied separately since they are different in form and they possess unique properties and powers. The three milieus of structure, culture, and agency are superimposed on each other and these milieus constrain or enable the actions of the agents. The structural milieu (Archer, 1995) consists of roles, organisations, institutional structures, such as SMTs, school governing bodies (SGBs) and the like, systems, policies, committees, substructures, and positional levels within the organisation. The structure may also include the material conditions which would motivate action (Archer, 2003). Culture mainly focuses on the way of life of a particular group of people. It encompasses behaviour, beliefs, values, customs, relationships and special symbols. Agency refers to the personal and psychological makeup of individuals and their social roles. It relates to the capacity people have to act voluntarily. Application of Archer's (1995) theoretical insights offers a sound framework for explaining the relationships of structure, culture and agency to explore the effects of school leadership in enhancing learner performance. I argue that principals, together with their SMTsm must attend to structural, cultural and agential properties and powers in schools.

\section{RESEARCH QUESTIONS}

An interview guide with the following research questions were used:

1. What are you doing in your school to improve performance?

2. What is the leadership's secret for achieving school improvement?

3. What is being done by the leadership to enhance the culture of teaching and learning?

4. How are organisational structures in the school ensuring effective teaching and learning?

5. What are the formal actions, if any, that are being carried out by the leadership to enhance teaching and learning?
6. How are you and your SMT ensuring effective teaching and learning?

\section{METHODOLOGY \\ Research Design}

Qualitative evidence was collected from six schools in the same district, selected through purposive sampling. Qualitative research was adopted because it provides the researcher with an opportunity to probe for opinions from participants in a natural setting. The design was used to capture the richness of the lived experiences of principals and teachers. A qualitative approach emphasises the qualities of entities, processes and meanings that are not experimentally examined or measured (Creswell, 2014). Researchers suggest the need for qualitative studies (Creswell, 2007) to capture the thinking and actions of participants within their context. The interpretive paradigm and the specific phenomenological design enabled the researchers to look, hear and understand the particular meaning-making inherent in people's lives within the selected schools. Using purposive sampling, with the assistance of the area manager, three secondary schools, one combined school and two primary schools that were considered to have changed from underperforming schools to improvedperformance schools were selected. Purposive sampling was deemed a valid form of sampling, used with a phenomenological research design where the researchers chose information-rich cases to explore the perceived effects of leadership on school improvement. The principal sources of data were semistructured interview questions through which we worked to understand the world from the perspective of the participants. We were interested in the role of leadership in improving school performance.

\section{Data collection}

The strong desire to collect data that reflected the perspective of our study participants resulted in the choice of in-depth unstructured interview questions. Creswell (2014) asserts that 
interviews present the researcher with the means to access the experiences, knowledge, thoughts and feelings of participants. Data collection took about one hour with each participant which was the intended duration for the interviews and data was gathered in November 2016. Throughout the collection of data we were guided by Bernard's (2002: 206) advice that "the idea is to get people to open up and let them express themselves in their own terms and at their own pace". Interviews were conducted with the principal and two senior teachers selected from each school. We decided to limit the interview questions to six to enable participants to remain focused on the research problem.

\section{Establishing trustworthiness and credibility}

In seeking trustworthiness and credibility (Lincoln \& Guba, 2000), the researchers should be concerned with activities that increase the probability that credible findings will be produced. To ensure trustworthiness and credibility, we used Creswell's (2014) norms of trustworthiness. These are prolonged engagement which is an investment of sufficient time to achieve certain purposes, learning from the participants, testing for misinformation introduced by distortions of the self or the participants and building trust. We also used member checks by requesting an external coach from a university in Zimbabwe who is familiar with school leadership to review the accuracy of the manuscripts and explanations of the sequence of events and ideas. To confirm our interpretations and enhance the credibility of our findings, we consulted with participants throughout the conduct of the study (Lincoln \& Guba, 2000). We also consulted with other researchers based at North-West University, who provided the necessary triangulation.

\section{Ethical considerations}

Consent to collect data from the schools was obtained from the Ethics Committee of North-West University, Potchefstroom Campus, the Superintendent of Education of the North
West Department of Education and Sport Development, the District Director of Education for $\mathrm{Dr}$ Kenneth Kaunda District, and all the participants in the study. In all cases, we explained to the participants' satisfaction the purpose of the study and the goals of the research. Participants were made aware that they could withdraw from the research at any time without incurring any consequences. It was also stressed that confidentiality and anonymity would be observed during the study and after its conclusion. During the interviews, the principals were coded as "P1" to "P6", while the teachers were referred to as "T1 S1"(meaning "first teacher from the first secondary school"), "T2 S2", and so on. Pseudonyms were used to protect the identities of the schools that participated in the study.

\section{RESULTS}

Grounded in the accounts of our study participants, this descriptive narrative highlights the key findings of the study. Qualitative analysis of data was conducted using frameworks consistent with the grounded theory approach (Creswell, 2014). Once the interviews had been conducted and were transcribed, we captured the accounts of the experiences of each participant on spreadsheets.

The six schools investigated in the study were as follows (pseudonyms are used for the schools):

1. Ruben, a secondary school with 1,452 learners and 44 teachers;

2. Maria, a secondary school with 1,475 learners and 40 teachers;

3. Joseph, a primary school with 1,037 learners and 30 teachers;

4. Modester, a secondary school with 526 learners and 19 teachers;

5. Glady, a combined farm school with 618 learners from Grade R to 12 and 20 teachers, where the majority of the learners are drawn from the farming community; and

6. Norah, a primary school with 1,023 learners and 30 teachers.

The study established that the six schools are facing multiple challenges such as constant burglary, poverty among the communities, unfilled posts 
for educators, especially for HODs, teenage pregnancies, child-headed families, and acute social and economic challenges.

\section{Principal leadership and school improvement}

The main purpose of the study was to understand the effects of leadership in enhancing quality learning outcomes in schools. The literature review of the study highlighted the importance of leadership in ensuring a culture of teaching and learning. In addition, the participants in the study constantly emphasised the critical role played by the principal in enhancing learner achievement. All the principals maintained that they play a crucial role in ensuring school improvement. For example, the principal of Joseph Primary School asserted that

I am the key figure in leading the processes of teaching and learning. Well, I give others the opportunity to lead but I continually double-check the activities of teachers and learners. I create a climate of high expectations, and for your information, I conduct regular accountability sessions with my teachers. Teachers in this school work hard, because I also work hard to support them. We work as a team. I provide for democratic leadership. Teachers are motivated.

It was clear from the data provided by both the teachers and the principals that the leadership in the schools was democratic as teachers participated in decision-making and schools used teams to achieve high performance among their learners. There was an indication that in all the schools, teachers are well motivated and they work as a team to achieve their goals. One of the teachers from Glady Combined School commented as follows in this regard:

You cannot tell that some of us are foreigners. We are so motivated to remain in this school. I don't think I will move out of this school. We are treated equally here. We are respected. We set our targets with the principal and he is at the forefront in assisting us to achieve our targets. We are rewarded for good performance and as a result, we all do some extra lessons with our learners.

A frequent response from the teachers was that their principals shared ideas with them and that this created a sense of shared ownership and commitment among the teachers. $\mathrm{Ng}$ (2013) believes that sharing ideas with colleagues in a workplace generates a sense of shared ownership and commitment to resolution of problems and that inviting a diversity of openly expressed views enhances motivation and articulation of imaginative insights. This broadens the range of solutions.

We asked participants what the role of principal leadership was in sustaining school improvement. Both the teachers and the principals identified the following key issues:

1. Putting in place plans that support improved academic achievement;

2. Principals motivating teachers through rewards and recognition;

3. Principals managing the instructional programme so as to build a productive school culture;

4. Setting high expectations, monitoring both teachers and learners, and ensuring close monitoring by the SMT;

5. Promoting continuous professional development for teachers;

6. Defining school goals, and ensuring achievement of these goals;

7. Principals leading school improvement by ensuring that there are high standards;

8. All teachers seeking to be winners;

9. Commitment to the core values and vision of the school;

10. Commitment to the pursuit of excellence in all aspects of school life;

11. Commitment to the development, empowerment and support of everyone in the school; and 


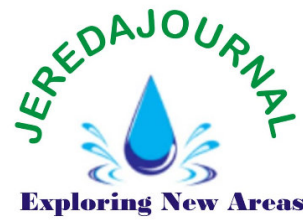

12. Leading teaching and learning in the school.

The evidence from the study points to a deliberate attempt by the school principals to create conditions where the teachers felt motivated. This, in turn, increased the teachers' productivity and commitment at work. The importance of good leadership for school turnaround is confirmed by Leithwood, Mascall and Strauss (2006: $5)$, who point out that there is not a single documented case of a "school successfully turning around its pupil achievement trajectory" in the absence of good leadership.

\section{Leadership and enhancing the culture of teaching and learning}

The concept of creating a culture of teaching and learning is widely used in the context of African systems of education. It refers to the attitudes of all stakeholders towards the provision of quality teaching and learning in the school, where all stakeholders value the processes involved in teaching and learning. A culture of teaching and learning refers to the integration of all activities in the school that would promote effective teaching and learning by developing organisational structures and instructional programmes that focus specifically on the teaching and learning processes in the school. It was interesting to note in the study that restoration of a culture of teaching and learning was cited as imperative in the schools. Our study participants asserted that principals were making an effort to restore a culture of teaching and learning by

1. Creating a school organisation where all members understand that every learner must be supported,

2. Giving high priority to teaching and learning,

3. Devoting more time to learning activities,

4. Creating conditions in the school where learners can receive quality instruction,
5. Creating good relationships between teachers, learners and parents,

6. The principal taking the responsibility to ensure that effective teaching and learning takes place,

7. All players in the school system valuing the process of teaching and learning,

8. Establishing a positive culture of teaching and learning at school and at home,

9. Encouraging learners to do their homework,

10. Encouraging parents to assist learners with their homework,

11. Involving parents in decisionmaking and problem-solving,

12. Creating a climate of inquiry that challenges the school community, and

13. Promoting a culture of achievement for all learners by communicating and implementing a common vision and mission that is shared by all stakeholders.

The principal of Modester

Secondary School noted that:

$[w] e$ involve parents in solving problems in the school. We have done that on several occasions, especially on issues relating to learner discipline. There is always active participation where both teachers and parents are actively involved in core developmental school programmes, and our parents have taken an active role in shaping our teaching and learning activities.

All participants emphasised that principals work hard to ensure a culture of teaching and learning.

\section{Organisational structures in schools to provide for school improvement}

A review of the responses on the question related to school organisational structures established to promote improvement shows that the participants interviewed indicated that principals understand the critical role organisational structures play in improving learner performance. In response to the 
structured reforms of decentralisation in the South African education system, principals have embarked on creating structures in schools in a drive to enhance the culture of teaching and learning. All participants showed a clear understanding of organisational structures in schools, and the roles that these structures perform to enhance the achievement of school improvement. The principals interviewed indicated that they have initiated structures such as:

1. Asking everyone involved in the school for suggestions on how to change and improve processes and situations in the school,

2. Establishing disciplinary committees involving parents, ccountability-monitoring

structures, Site-based management structures made up of heads of departments (HODs), SMTs, and senior supervision teams,

3. Creating an atmosphere of transparency in working towards common goals,

4. Appointing subject heads, and

5. Appointing extracurricular coordinators.

The principal of Norah Primary School indicated that:

[w]e have established structures

and methods of instructional

management, and we rely on the

involvement and leadership of a

number of teachers. These

structures are very active and

they play a crucial role in the

supervision of both learners and

teachers.

The need to distribute responsibilities and create structures is in line with Özdemir and Demircioğlu (2015), who have emphasised the importance of sharing, participation and democratic principles. School-based management structures in the schools were seen to be spreading leadership throughout the school. Such leadership has been described as distributed leadership (DL), which is an approach of spreading leadership organisation-wide.

\section{Agential actions to enhance teaching and learning}

During the interviews, participants were asked what agential actions have been adopted by teachers and other related agents to enhance teaching and learning. On this question, participants had different views, since they were not clear what the term "agents" refers to. All participants indicated that the term "agents" was new to them. However, after it was explained to them that the term "agents" refers to the personal and psychological makeup of individuals and their social roles, and to the capacity of people to act voluntarily, they understood what was meant by the term. In their reports, participants highlighted that the principal as a change agent in the school is responsible for stimulating change. The principal manages the instructional programme so as to build productive school culture. The key agential actions of the principal were summarised as follows:

1. Setting high expectations and monitoring teachers;

2. Conducting accountability sessions with teachers;

3. Managing the instructional programme;

4. Motivating members;

5. Ensuring availability and deployment of the necessary resources required for effective teaching;

6. Principals act as key players in ensuring quality learning outcomes;

7. Encouraging teamwork among teachers; and

8. Stimulating change in the school. All participants maintained that the principal is a key change agents in their schools although there was power sharing where teachers with expertise played a significant role in leading others. One of the teachers (T2S2) asserted that

[t]he principal of this school is a key agent of change. He is the one responsible for establishing teams. We work hard because of his motivational strategies. Change is stimulated by him. He is hardworking. He is focused on 


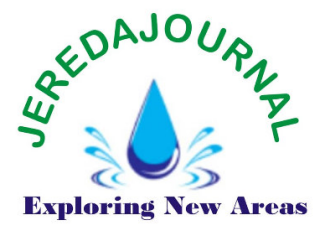

school improvement. We also work hard in this school to improve learner performance.

All these responses are in line with Leithwood, Harris and Hopkins (2008), who confirm that a school leader stimulates change by analysing the organisational needs for change. In most of the responses, especially those of the teachers (namely T1 S1, T2 S1, T1 S2 and T2 S2), issues such as encouraging teamwork and motivating members were highlighted.

\section{The role of SMTs in providing for effective teaching and learning}

In all the schools investigated in the study, participants commented that the principal shares the instructional leadership role with their HODs and their SMT and that there is a shared sense of purpose. The principal of Joseph Secondary School stated that

$[\mathrm{m}] \mathrm{y}$ teachers take turns to chair meetings. Everyone here is a leader. I delegate my SMT members to run the school. There is active participation among all members of staff. My SMT plays an important role in monitoring and supervising both teachers and our learners. Each time I call for parents meeting, I will be joined by my SMT and they provide significant contributions in the interest of learner achievement. My team is very active. They are motivated.

As is evident from the above response, the findings of this study point to the idea that principals and their SMTs are responsible for ensuring that school improvement is achieved by creating and stimulating a positive work environment for members of staff. This is done through motivating staff, involving them in decision-making, developing other members of staff and ensuring that the school progresses. The study participants indicated that they believe in and wish to work with an SMT that

1. Focuses on teachers' efforts,
2. Appreciates different opinions from members of staff,

3. Emphasises inspiration and motivation of staff members,

4. Monitors teachers regularly,

5. Recognises good instructional practices that motivate and increase learner achievement, and encourages others to learn and implement such practices,

6. Delegates responsibility according to proper management and leadership practices, accountable in all matters concerning the school,

8. Develops and supports other leaders within the school community,

9. Takes responsibility for a safe, secure and disciplined school environment,

10. Shares and transmits ideas and stimulates decision-making on pedagogy and welfare issues with all staff members,

11. Promotes achievement of the school's mission statement,

12. Identifies problems and challenges, and finds solutions that enhance teaching and learning, and

13. Monitors implementation of school plans and ensures that objectives are achieved by applying the necessary interventions.

These issues have also been noted by Yang (2014) who emphasises the importance of transformational leadership in schools. In all the six schools, the leadership professed to serve all members of the school community by focusing on creating educationalpreparation programmes that have a strong emphasis on teaching and learning. Based on the literature review and the research findings, the critical component of hard work and accountability in the SMT was seen to be the key ingredient for enhancing learner achievement in schools.
7. Takes responsibility and is 
Journal of Educational Research in Developing Areas (JEREDA)

Vol. 1. Issue 3, Pp. 202-213, 2020

http://www.jeredajournal.com

E-mail: info@jeredajournal.com

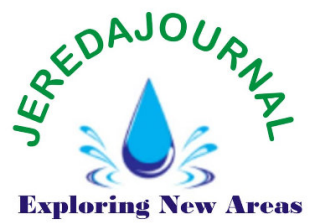

\section{DISCUSSIONS}

Leadership and learner achievement

The purpose of this study was to examine the effects of school leadership in enhancing learner achievement. Scholars have noted that the literature on educational leadership and management has been dominated by contributions from English-speaking Western societies and consequently, in Africa understanding of how educational leadership influences learning outcomes is limited. Recognising this limitation, this study conducted in South African schools established that principal leadership is essential for promoting learner achievement. It can also help the school solve problems appropriately. It can also lead to various improvements in the school set-up. The potential leadership skills of the principal are seen in forming and creating a vision for the school. This is in line with Boylan (2016) who tells us that principal leadership plays a key role in school improvement. In this study, we argue that schools at different stages of development will also need different leadership emphases. Clearly, based on the findings of this study, what is essential to a leader's ability to improve teaching and learning is motivational strategies, collaborative decision-making and interpersonal skills which should be essential for leadership.

The study established that school leaders and staff work together to review and improve teaching. Leadership in the schools investigated in the study is directly involved in coordinating the curriculum across the school. This includes activities such as setting of goals and development of progressions of teaching objectives. Involvement of the principal in classroom observation and subsequent feedback was also associated with higher performance. Principals also systematically monitor student progress. The findings of this study show that the principal together with their SMT and HODs play a crucial role in planning, coordinating and evaluating teaching and the curriculum. In all schools investigated in the study, principals make student achievement the school's top goal. Successful leadership was seen to be

influencing teaching and learning through face-to-face interaction and through stimulating the way teachers do their work.

\section{CONCLUSION}

This study on the effects of school leadership on enhancing learning outcomes concluded that principal leadership directly contributes towards learner achievement. This conclusion was reached based on the literature review and the findings of the study which was conducted in six schools in South Africa. The study established that principals in the schools play a crucial role in establishing goals and expectations, in strategic resourcing for effective teaching and learning, in planning, coordinating and evaluating teaching programmes, and in ensuring an orderly and supportive teaching and learning environment. The process of setting, communicating and monitoring of goals, standards and expectations for the schools involved full participation of the teachers and the parents in the process so that there was clarity and consensus on the general operation of the school. The leadership in all the schools was reported by the teachers to be among other things, focused on teaching and learning and specifically on directly coordinating the work of teachers, learners and parents.

In all cases, the principals were seen by the teachers as a source of motivation, staff development and instructional advice. The principals were significantly regarded as sources of advice and as playing a major role in improving teaching and learning. In this study, we conclude that leadership in schools involves not only building collegial teams and cohesive staff but also sharing an inspirational vision and especially focusing on pedagogical work. In short, the study concludes that the essential tools for enhancing a culture of teaching and learning are accountability, monitoring and staff development, with a specific focus on schools in aligning structure, culture and agency. This will create the best prospects for ensuring sustainable school learner achievement and enhancing learner performance. 


\section{Conflict of Interest}

The authors declare no conflicts of interests.

\section{Acknowledgement}

We acknowledge the generous funding from the North West University Post-Doctoral funding. We also acknowledge the open participation by principals and the significant role play by Prof. J. Heystek for moderating our interview questions.

\section{Authors' Bionotes}

Dr. G. N. Shava is a Senior Lecturer at the National University and Technology, Faculty of Science and Technology Education. He has extensively researched and published in the following areas: Education leadership, quality higher education and education for sustainable development. He was awarded the most productive postdoctoral research fellow by the North West University for 2017, awarded SANORD research award for 2019 and selected for the Erasmus Visiting Scholar to Uppsala University Sweden for 2021.

Dr. L. Sibanda is a Senior Lecturer at the National University and Technology, Faculty of Science and Technology Education and currently acting Dean for the Faculty of Science and Technology Education. She has extensively published in areas such as Assessment and evaluation and discipline.

\section{Authorship and level of contribution}

The article was produced by both of us with the same amount of contribution in data collection and production of manuscript.

\section{References}

Archer, M. S. (1995). Realist socialist theory: The morphogenetic approach. Cambridge University Press.

Archer, M. S. (2003). Structure, agency and the internal conversation. Cambridge University Press.

Bernard, H. R. (2002). Research methods in anthropology: Qualitative and quantitative approaches. 3rd ed. Walnut Creek. Altamira Press.

Bhaskar, R. (1978). A realist theory of science. 2nd ed. Harvester.

Boylan, M. (2016). Deepening system leadership: Teachers leading from below.Educational Management Administration \& Leadership, 44(1), 57-72.

Cosner, S. (2011). Teacher learning, instructional considerations and principal communication: Lessons from a longitudinal study of collaborative data use by teachers. Educational Management Administration \& Leadership, 39 (5), 568-589.

Cotton, K. (2003). Principals and student achievement: What the research says. Association for Supervision and Curriculum Development.

Creswell, J. W.2007.Qualitative inquiry and research design: Choosing among five approaches. 2nd ed. Sage.

Creswell, J. W. (2014). Research design: Qualitative, quantitative, and mixed methods approaches. 4th ed. Sage.

Department of Basic Education. 2016. National Education Policy Act,1996 (Act 27 of 1996): Policy on the South African Standard for Principals. Gazette 39827. Government Printing Works.

Hallinger, P. (2005). Instructional leadership and the school principal: A passing fancy that refuses to fade away. Leadership and Policy in Schools, 4 (3), 221-239.

Harris, A. (2004). Distributed leadership and school improvement: Leading or misleading? Educational Management Administration \& Leadership, 32 (1), 11-24.

Heystek, J., \& Minnaar, L. (2015). Principals' perspectives on key factors that contribute to sustainable quality education. Journal of Education, 63, 137-157.

Hoy, W. (2012). School characteristics that make a difference for the achievement of all students: A 40- 
year odyssey. Journal of Educational Administration, 50 (1), 76-97.

Klar, H. W., Huggins, K. S., Hammonds, H. L., \& Buskey, F. C. (2016). Fostering the capacity for distributed leadership: A postheroic approach to leading school improvement. International Journal of Leadership in Education, 19(2), 111-137.

Krüger, M. L., Witziers, B., \& Sleegers, P. (2007). The impact of school leadership on school level factors: Validation of a causal model. School Effectiveness and School Improvement, 18 (1), 1-20.

Leithwood, K., Harris, A., \& Hopkins, D. (2008). Seven strong claims about successful school leadership. School Leadership \& Management, 28 (1), 27-42.

Leithwood, K., Mascall, B., \& Strauss, T. (2009). Distributed leadership according to the evidence. Routledge.

Lincoln, Y. S., \& Guba, E. G. (2000). Epistemological and methodological bases for naturalistic inquiry. Sage.

$\mathrm{Ng}$, S. W. (2013). Equipping aspiring principals for the principalship in Hong Kong. Educational Management Administration \& Leadership, 41 (3), 272-288.

Özdemir, M., \& Demircioğlu, E. (2015). Distributed leadership and contract relations: Evidence from Turkish high schools. Educational Management Administration \& Leadership, 43 (6), 918-938.

Robinson, V. M. J., Lloyd, C. A.\& Rowe,K.J. 2008. The impact of leadership on student outcomes: An analysis of the differential effects of leadership types. Educational Administration Quarterly, 44(5), 635-674.

Sayadi, Y. (2016). The effect of dimensions of transformational, transactional, and non-leadership on the job satisfaction and organizational commitment of teachers in Iran. Management in Education, 30 (2), 57-65.
Shava, G. N., \& Heystek, J. 2015. Achieving educational goals through effective leadership: Experiences from a district in Zimbabwe.Journal of Educational Studies, 14(2), 1-24.

Shava, G. N., \& Ndebele, C. (2016). Enhancing learner achievement through effective school leadership: Experiences from selected rural schools in South Africa. International Journal of Educational Sciences, 14 (3), 205216.

Stake, R. (1995). The art of case study research. Sage.

Storey, A. (2004). The problem of distributed leadership in schools. School Leadership \& Management, 24(3), 249-265.

Waters, J. T., Marzano, R. J., \& McNulty, B. (2004). Leadership that sparks learning. Educational Leadership, 61(7), 48-52.

Witziers, B., Bosker, R. J., \& Krüger, M. L. (2003). Educational leadership and student achievement: The elusive search for an association. Educational Administration Quarterly, 39 (3), 398-425.

Wynn, D., \& Williams, C. K. (2012). Principles for conducting critical realist case study research in information systems. MIS Quarterly, 36 (3), 787-810.

Yang, Y. (2014). Principals' transformational leadership in school improvement. International Journal of Educational Management, 28 (3), 279-288. 